This is an open access article under the CC BY-NC-ND license

Issue IV, 22 November 2021

e-ISSN 2707-9481

Institute of Metallurgy and Ore Beneficiation, Satbayev University, Almaty, Kazakhstan

ISBN 978-601-323-252-2 https://doi.org/10.31643/2021.15

Uteshkalieva Aigul

Candidate of Pedagogical Sciences, Acting Associate

Professor of Kh. Dosmukhamedov Atyrau University

Email: aigul_bekbol@mail.ru

https://orcid.org/0000-0002-7571-6279
Kumarova Zulfiya

2nd year Master's student

OP 7M01301 -Management in Education

Kh. Dosmukhamedov Atyrau university

Email address: kumarova94@inbox.ru

\title{
Organizational and managerial conditions for creating a health-saving environment of an educational organization
}

\begin{abstract}
This article examines the organizational and managerial conditions for creating a health-preserving environment of an educational organization, presents a model of a health-preserving environment that contributes to increasing the levels of activity, positive cognitive motivation, interest, organization, independence of students of the educational space. Authors highlighted that it is necessary to properly organize students' individual educational and cognitive activities that correspond to individual capabilities and abilities, as well as the conditions of the educational environment.
\end{abstract}

Keywords: healthy lifestyle, health-saving environment, organizational and managerial conditions.

Cite this article as: Uteshkalieva A.; Kumarova Z. (2021). Organizational and managerial conditions for creating a healthsaving environment of an educational organization. Challenges of Science. Issue IV, pp. 99-102. https://doi.org/10.31643/2021.015

\section{Introduction}

The current state of society and the pace of its development place ever higher demands on a person and his health. The wealth of any state is not only natural resources or material and cultural values, although they are undoubtedly important, but also, first of all, the people who inhabit it. In a short period of time during the pandemic, significant changes took place in society in almost all spheres of life: politics, economics, education, medicine, etc. The very perception of a person, his moral guidelines and life values have also changed.

Social problems and economic difficulties of recent years in the Republic of Kazakhstan have led to a significant decrease in the standard of living of the population, difficulties in psychological adaptation to changes in the country. All this has negatively affected the health of a significant part of the population.

\section{Main Research part}

As you know, health is not only an important indicator of social development, but also a powerful economic, labor and cultural potential. There are negative trends in the health of the younger generation, especially the increase in morbidity, changes in the indicators of physical development of children and adolescents, irrational and inadequate nutrition of children for the entire period of their education in educational institutions, the development and implementation of measures to eliminate them are constantly in the field of view of scientists.

The problem of organizing a health-preserving environment is considered in sociological, medical and pedagogical research. N.A. Amosov [1], I.I. Brekhman [2], E.P. Weiner [3], N.P. Lisitsin [4], the pedagogical and methodological basis of the health-preserving environment is covered in the works of V.V. Kolbanov, G.K. Zaitsev [5]. 
Materials of International Practical Internet Conference "Challenges of Science", Issue IV, 2021

Educational Organizations

(Preschool Education, Secondary Schools (Lyceums, Gymnasiums), Secondary Educational Institution, Universities)
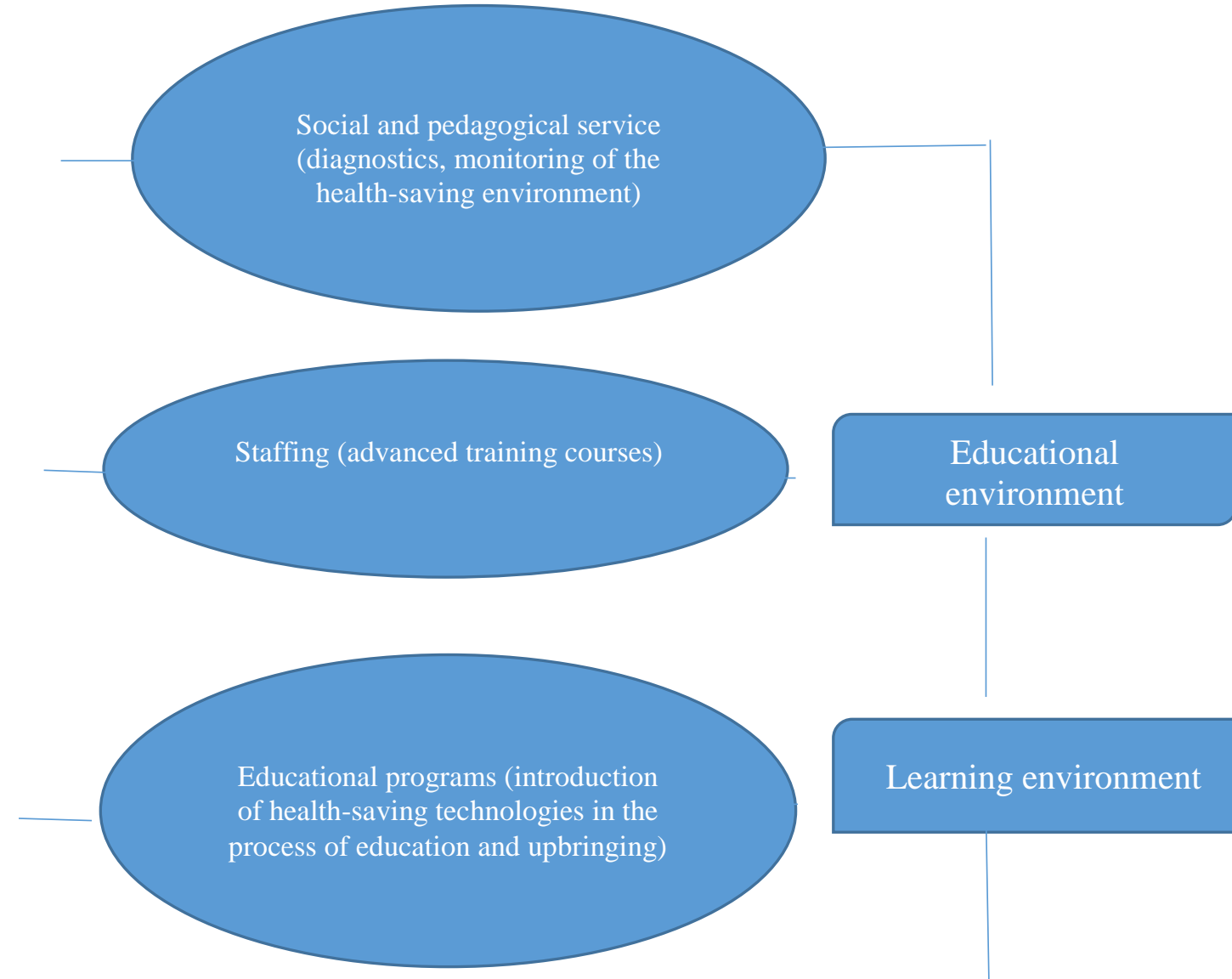

Learning environment
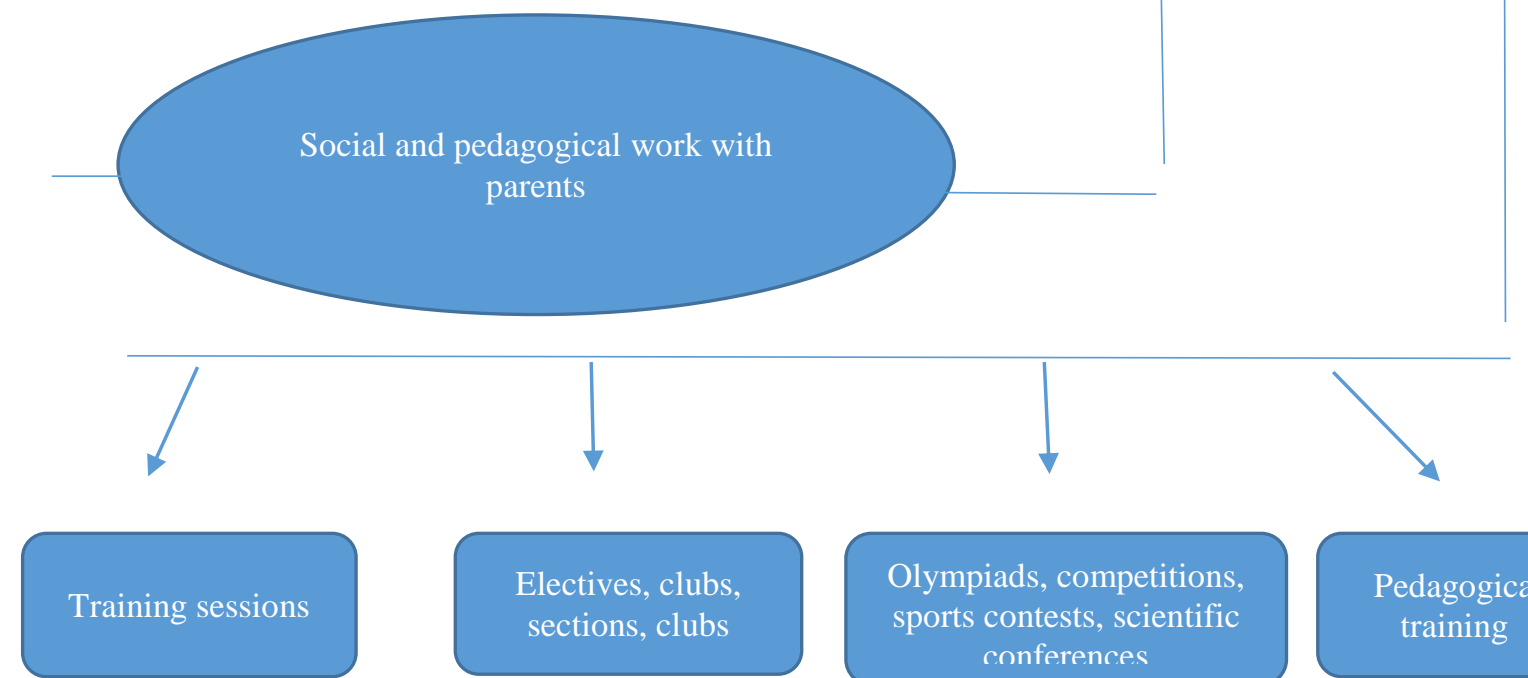

Electives, clubs, sections, clubs

Olympiads, competitions, sports contests, scientific conferences

Health-Saving Environment of an Educational Organization

Figure 1 - Model of the health-saving environment of an educational organization 
The research of the scientific foundations of the formation of a health-preserving environment in educational institutions is highlighted in the works of domestic scientists H.K. Satpayev [6], A.S. Imangaliev [7] and others.

Value orientations to a healthy lifestyle, sustainable needs for the preservation and improvement of health, the use of effective means of organizing a rational mode of education and active recreation, physical education and sports are formed with the provision of appropriate pedagogical conditions aimed at organizing a health-preserving environment of education.

An educational institution should create conditions that guarantee the protection and strengthening of the health of students and pupils.

During the analysis of the current state of the problem under study and scientific and methodological literature, we have identified organizational and managerial conditions that contribute to the creation of a health-saving environment of an educational organization:

$>$ the integrity of the system of forming a culture of healthy and safe lifestyle of students and pupils. The systematic nature of the activity is considered on issues of health protection and promotion, the interaction of an educational institution with executive authorities, law enforcement agencies, scientific institutions;

$>$ continuity and continuity of learning a healthy and safe lifestyle;

$>$ an integrated approach and continuity in providing psychological, pedagogical, medical and social support to various groups of students, pupils;

$>$ the formation of a health culture of pedagogical and scientific-pedagogical workers of an educational institution);

$>$ rational organization of the educational process: inclusion of educational programs, projects with the use of forms, methods of teaching and upbringing, pedagogical technologies that are adequate to age-related opportunities and features for the formation of a culture of a healthy and safe lifestyle, providing favorable psychological conditions for the educational environment of students and pupils;

$>$ organization of the work of sports sections, clubs, clubs, educational, extracurricular (extracurricular) activities of a physical culture and wellness orientation at each stage of general education and in the system of vocational education;

$>$ organization of a system of educational and methodological work with participants of the educational process on healthy and safe lifestyle;

$>$ professional development of pedagogical and scientific-pedagogical workers on various issues of the health-preserving environment (age psychology and physiology, human development, his health, factors that positively and negatively affect the health and safety of students, pupils);

$>$ monitoring of the formation of a culture of healthy and safe lifestyle of students, pupils (availability of analytical data on the formation of the value of a healthy and safe lifestyle among students, pupils, contributing to the creation of a health-preserving environment.

The above organizational and managerial conditions for creating a health-saving environment of an educational organization contributed to the development of a model for the implementation of the educational space by moving from the management of educational organizations to the management of educational programs (Figure 1).

The presented model is a condition for self-development, self-education and personal training at different levels of the organization of knowledge acquisition by students, as well as continuity between different types of institutions is built.

Having studied the scientific and methodological literature on the problem under study [8, $9,10]$, we took into account the principles of formation and organization of a health-saving environment in an educational organization during the implementation of the developed model in practice, namely:

$>$ the principle of naturalness (taking into account the age and individual characteristics of students);

$>$ the principle of consciousness and activity (the formation of value orientations for a healthy lifestyle, its conscious personal inclusion in programs for the preservation and strengthening of one's own health);

$>$ the principle of priority of the student's personal development; 
$>$ the principle of scientific approach in the organization of scientifically based and proven healthsaving technologies);

$>$ the principle of connection of theory with practice (practice-oriented approach);

$>$ the principle of value orientation of the educational process (ensuring the unity of the formation of a healthy and intellectually developed personality);

$>$ the principle of subjectivity of health-saving educational process (freedom of choice in the learning process, taking into account one's own interests and the state of his physical and mental development).

Our research is a set of measures of the educational process in the educational organization system, which should ensure that students achieve high levels of activity, positive cognitive motivation, interest, organization, independence, interest in obtaining a quality result.

The diverse nature of existing developments in the content, forms and methods of educational work is explained by differences in setting specific research goals, the evolving nature of society's requirements for specialists and other factors. The creation of organizational and managerial conditions is based on the use of certain forms and methods of work, with the help of which the necessary atmosphere of the team is achieved.

As for the forms of monitoring and evaluating the effectiveness of activities in the process, in which each student individually and creatively, in accordance with their abilities and capabilities, solves the tasks set, also traditional methods of observation: survey, interviewing, programmed control, performance of written and artistic tasks, testing, analysis of products of activity, statistical data processing.

\section{Conclusion}

To meet the educational needs of participants in the educational space, it is necessary to properly organize their individual educational and cognitive activities that correspond to individual capabilities and abilities, as well as the conditions of the educational environment in which the activity is carried out. Undoubtedly, the state of success gives confidence, new strength, which forms students' higher educational needs.

Cite this article as: Uteshkalieva A.; Kumarova Z. (2021). Organizational and managerial conditions for creating a healthsaving environment of an educational organization. Challenges of Science. Issue IV, pp. 99-102. https://doi.org/10.31643/2021.015

\section{References}

1. Amosov N.M. Thoughts about health. 3rd ed. - M.: Physical culture and sport, 1987.- 64 p.

2. Brekhman I.I. Valeology - the science of health. - 2nd ed., supplement, revision-M.: Physical culture and sport, 1990. - 208 p.

3. Weiner E.N. Valeology. Flint Publishing House, Science, 2001. Pp.59-66.

4. Lisitsin Yu.P. A word about health. Moscow: 1986, 192 p.

5. Zaitsev G.K., Kolbanov V.V. The strategy of understanding a healthy lifestyle among teachers // Valeology: Diagnostics, means and practice of ensuring health. Vladivostok: Dalnauka, 1996. Issue 3, pp. 148-153.

6. Satpayeva H.K., Valeology is the science of health. Educational and methodical manual. - Almaty: Gylym, 1999.-8s.

7. Imangaliev A.S. Pedagogical valeology. Almaty.: Alem, 1998, 262s.

8. Likhachev B.T. Pedagogy. Course of lectures 4-ed. Yurayt, M.:2000, From 523.

9. Smirnov N.K. Health-saving educational technologies in the work of teachers and schools. - M. - 2003. - $242 \mathrm{p}$.

10. Quality management of education, edited by M.M. Potashnik, M.2006. 